\title{
Objetivo: proteger la exclusiva. Los límites imprecisos del periodismo de chequera
}

Recibido: 29/09/2011

\author{
Antonio LóPEz HidALGO \\ Universidad de Sevilla \\ lopezhidalgo@us.es \\ Ángeles FERnÁndEZ BARRERo \\ Universidad de Sevilla \\ mfernandez10@us.es
}

Aceptado: 13/03/2012

\section{Resumen}

El fin del periodismo de chequera es garantizar informaciones en exclusiva. Pese a que el pago a las fuentes de información no convence en todos los países ni entre la prensa de calidad, esta fórmula está ampliamente extendida en televisión, donde la guerra de audiencias lleva a numerosos programas a recurrir a métodos éticamente dudosos para proteger sus exclusivas. El objetivo de este ensayo es teorizar sobre esta práctica, que en las últimas décadas adopta nuevas fórmulas al margen del pago en efectivo. La revisión crítica de la bibliografía existente y el análisis descriptivo de casos representativos evidencian los límites imprecisos del periodismo de chequera, que incluye una amplia variedad de fórmulas de pago, pero también de los agentes que intervienen en el proceso y la mercancía que se comercializa.

Palabras clave: Fuentes, periodismo de chequera, exclusiva, ética periodística.

\section{Ensuring Scoops: The Vague Boundaries of Checkbook Journalism}

\begin{abstract}
The goal of checkbook journalism is to ensure scoops. Although the practice of paying sources of news reporting does not like in all countries or in respectable media, this formula is widespread in TV networks, where the war for audiences has led many programs to use questionable methods, from an ethical perspective, in order to protect their exclusives. The aim of this paper is to theorize about this practice, which has adopted many ways in the last decade, apart from traditional cash payments. From a methodological point of view, we include a critical literature review and a descriptive analysis of representative cases. The results of the investigation reveal the vague boundaries of checkbook journalism, which includes a wide variety of payment modes, the actors involved in the process and the merchandises sold. Keywords: Journalistic Sources, Checkbook Journalism, Scoop, Journalistic Ethic.
\end{abstract}

\section{Referencia normalizada}

LÓPEZ HIDALGO, Antonio y FERNÁNDEZ BARRERO, Ángeles (2012): “Objetivo: proteger la exclusiva. Los límites imprecisos del periodismo de chequera". Estudios sobre el mensaje periodístico. Vol. 18, núm. 1, págs.: 115-125. Madrid, Servicio de Publicaciones de la Universidad Complutense.

Sumario: 1. Introducción. 2. El periodismo de chequera. 3. El valor de la información. 4. Regulación ética. 5. Estudio de caso: la entrevista del programa de Ana Rosa Quintana a Isabel García. 6. Conclusiones. 7. Referencias bibliográficas.

\section{Introducción}

El objetivo del periodismo de chequera siempre es el mismo: proteger informaciones en exclusiva. Sin embargo, esta etiqueta, que designa la práctica de pagar por la información suministrada por determinadas fuentes, ha adoptado con el tiempo numerosas variantes que precisan una revisión crítica del concepto. El propósito de este estudio es analizar, desde una perspectiva cualitativa, los nuevos límites de este rótulo, 
que incluye numerosos matices en cuanto a los agentes que intervienen en el proceso, la mercancía que se comercializa y, sobre todo, las formas de pago, entre las que el desembolso de efectivo es tan sólo una modalidad.

Con la finalidad de responder a estos objetivos, se ha recurrido a la revisión crítica de la bibliografía existente para el establecimiento de un marco teórico actualizado que permita visualizar las distintas perspectivas en torno a este fenómeno. Aunque se trata de una práctica conocida en el ejercicio de la profesión, la bibliografía en castellano es, sin embargo, escasa; no existen monografías y las contadas referencias se incluyen en manuales genéricos sobre ética periodística o en publicaciones periodísticas. Por ello, se ha recurrido especialmente a publicaciones estadounidenses. Especialmente de utilidad ha sido el manual de Ron F. SMITH o las investigaciones de Nick HighAm y Robert BOYNTON. El estudio incluye igualmente numerosas referencias a casos concretos y representativos que reflejan precisamente la variedad de matices que puede adquirir el concepto. Asimismo, incluimos un estudio de caso, un análisis pormenorizado de la entrevista de la cadena de televisión Telecinco a Isabel García, la esposa del presunto asesino Santiago del Valle, un caso que refleja los cuestionables métodos que se llegan a utilizar por proteger una exclusiva.

Tras la introducción, el trabajo se divide en cuatro grandes apartados. En el primero de ellos revisamos la definición de este concepto y las connotaciones que adquiere en distintas áreas geográficas en función de su uso por parte de distintos medios. En el capítulo tres nos adentramos en los distintos criterios respecto a su consideración ética y en la complejidad que implican las nuevas fórmulas de pago, los nuevos actores que intervienen en el proceso y el objeto, tangible o intangible, que se comercializa.

En el cuarto apartado revisamos qué postura asumen algunos códigos éticos ampliamente reconocidos en el ámbito de la profesión periodística y, finalmente, en el quinto capítulo, presentamos el estudio de caso. En el apartado de conclusiones incluimos los principales resultados de la investigación e identificamos nuevos parámetros que deben ser considerados entre los límites imprecisos del periodismo de chequera.

\section{El periodismo de chequera}

El periodismo de chequera, también conocido como checkbook journalism en los países anglosajones, es el término con el que se designa la práctica de pagar a las fuentes de información periodística por el suministro de datos o la concesión de entrevistas supuestamente privilegiadas, así como la realización de fotografías exclusivas.

El fenómeno es mucho más remoto de lo que en principio pudiera parecer. HEYBOER (1999) asegura que, sin una etiqueta concreta, la historia de la prensa es también una historia de periódicos que han pagado por historias de valor. Ya en 1912, por ejemplo, The New York Times consiguió una entrevista exclusiva con un radiotelegrafista del Titanic por 1.000 dólares.

El término, asimismo, se generaliza en la década de los sesenta, según Robert BOYNTON, profesor de la Universidad de Nueva York. En su ensayo para la revista Columbia Journalism Review, (2008) describe cómo la etiqueta se generaliza para describir las prácticas desarrolladas en los sesenta por la revista Esquire, que en 1963 
pagó a Muhammad Ali (entonces Cassius Clay) 150 dólares (1.000 dólares de hoy en día) por cooperar con un joven periodista llamado Tom Wolfe en su artículo "The Marvelous Mouth". Posteriormente, en 1970, el diario recurrió al mismo método para ilustrar el reportaje "The Confessions of Lt. Calley", que narraba la historia de un hombre que asesinó a cientos de civiles desarmados en el pueblo vietnamita de My Lai. Esquire le había pagado 20.000 dólares para trabajar con el veterano periodista John Sack.

Desde entonces, la práctica del periodismo de chequera se ha generalizado ampliamente, aunque con distintas consideraciones y matices en unos países y en otros. En el Reino Unido, por ejemplo, goza de gran tradición entre los tabloides, aunque la prensa de calidad (los broadsheets) también lo hace cuando le conviene, sin confesarlo abiertamente, como advierten OPPENHEIMER y GÓMEZ (2009), tanto para la información de sucesos como para la información política. "Los medios británicos nunca facilitan cifras, pero tienen menos pudor en el manejo del dinero a cambio de información en un mercado en el que la competencia es absolutamente feroz" (OpPENHEIMER y Gómez, 2009). El País cita como representativo el caso de la ex concursante del Gran Hermano británico Jane Goody, que convirtió su lucha contra el cáncer en un espectáculo de telerrealidad. Un mes antes se había casado en una ceremonia precedida de gran publicidad y cuyas imágenes se vendieron en exclusiva a la revista del corazón $O K$ y al canal temático Living $T V$ por un millón de libras. Ya en 1996, la británica Mandy Allwood arriesgó su vida al acordar con News of the World la venta de la exclusiva del nacimiento de sus octillizos por 125.000 libras por cada niño que naciera con vida, pese a que el ginecólogo que la asistía recomendó un aborto selectivo. Finalmente, Mandy Allwood perdió los ocho bebés.

En Estados Unidos es cada vez más frecuente la compra de vídeos en exclusiva entre las cadenas de televisión que emiten por Internet, aunque tampoco lo confiesan a no ser que se vean obligadas por lo evidente de algunos casos. Pese a ello, se sabe que la $C B S$ y la $C N N$ pagaron por piezas de vídeo en el que militantes de Al Queda envenenan a un perro con gas para hacer una prueba (SMITH, 2003: 187). Según Paul FARHI (2010), $A B C$ News y NBC News pagaron a familiares de tres de los mineros rescatados en Chile para que ofrecieran entrevistas exclusivas en los programas "Good Morning America" y el show "Today".

Mientras que en Estados Unidos en un principio se trató de una práctica reservada para tabloides como el National Enquirer, que llegó a pagar por exclusivas como la fotografía de Elvis en el ataúd, el periodismo de chequera se ha generalizado entre las estaciones de televisión y los sitios en Internet especializados en cotilleos, pero periódicos serios como The Washington Post y The New York Times han declarado abiertamente no pagar por informaciones o entrevistas.

En España es práctica habitual de la prensa del corazón, que comercializa con infidelidades, divorcios, embarazos y matrimonios, pero también de numerosos programas televisivos de corte sensacionalista. En los medios generalistas y en la prensa de calidad es un método censurado, o al menos no confesado. En la historia de la prensa del corazón en España se han pagado cantidades desorbitadas. Ya en 1989 se hablaba del precio de las exclusivas. En una tribuna de opinión en 1989, El País re- 
cordaba que la prensa del corazón pagó a Lola Flores y a su marido 36 millones de pesetas entre 1982 y 1985 , por diversas exclusivas en distintas revistas.

En cuanto al pago de programas televisivos, uno de los casos más notorios fue el desembolso que efectuó la cadena de televisión Telecinco por las entrevistas al ex alcalde de Marbella y ex pareja de la cantante Isabel Pantoja, Julián Muñoz, que había sido condenado por varios delitos urbanísticos y tenía pendientes al menos 60 causas judiciales por la concesión de licencias de obra ilegales. Esta cadena de televisión pagó 350.000 euros y Antena 3 llegó a ofrecerle 300.000, pero finalmente fue Telecinco la adjudicataria de la primera entrevista en exclusiva del ex alcalde tras salir de prisión en tercer grado penitenciario.

El acuerdo, según El Mundo (Longhi-Bracaglia, 2008), incluía una larga entrevista para trocear y emitir por entregas, más una comparecencia en un programa. Además, se alcanzó un pacto de no agresión entre el aludido y Telecinco, de manera que se retiraron tres demandas interpuestas contra la cadena y se acordó un conveniente olvido a la hora de reclamarle la responsabilidad subsidiaria en otras presentadas contra periodistas por sus intervenciones en programas de este canal. Telecinco también se relajaría en las informaciones emitidas centradas en la figura de Julián Muñoz. Los jueces ordenaron el embargo de las cantidades percibidas por el ex alcalde para garantizar su responsabilidad civil en las causas abiertas.

Lo cierto es que en España el hecho de pagar por informaciones no está bien visto. Blogueros e internautas, por ejemplo, se movilizaron para boicotear la repercusión de la entrevista a Julián Muñoz al hacer un llamamiento masivo para que nadie viera la entrevista, al tiempo que se animaba a que desde blogs y otros foros se recomendara a amigos y conocidos sumarse al acto de rechazo.

Aunque no hay demasiados sondeos que avalen este desafecto, El País publicó una pequeña encuesta entre sus lectores para ilustrar el reportaje "El periodismo de chequera tienta" (OPPENHEIMER y GÓMEZ, 2009), con una sola pregunta: ¿Deben los medios pagar por información de interés general? El resultado fue aplastante. Un $80 \%$ de los 1.533 lectores encuestados aseguraba que no, mientras que un exiguo $20 \%$ se mostraba partidario de pagar si la información merecía la pena.

Entre la prensa de calidad, pagar por la información de fuente no está bien visto. De hecho, tras la publicación de las filtraciones de Wikileaks, los directores de los cinco medios impresos seleccionados para revelar en exclusiva el contenido de los documentos clasificados, Le Monde, Der Spiegel, The Guardian, El Pais y The New York Times, se apresuraron para negar tajantemente esta posibilidad. En una entrevista digital realizada por los internautas, a la pregunta de si habían pagado algo por recibir esa información, el director de El País, Javier Moreno, aseguraba tajantemente: "No. El País no paga nunca por informaciones. Por esta tampoco" (El País, 2010)

\section{El valor de la información}

A favor del periodismo de chequera se esgrime generalmente el interés público de la información. Aún cuando desde algunos sectores se condena la práctica de pagar a las fuentes de información periodística por la información suministrada, se admiten algunos casos excepcionales, como el alto valor informativo aportado por la informa- 
ción, un factor en todo caso subjetivo. De igual modo, se contemplan con resignación otros supuestos, como la protección de una fuente en peligro.

En el año 2009, por ejemplo, la publicación por parte del diario británico The Daily Telegraph del detalle de los gastos de diputados, que sacó a la luz el derroche de sus señorías, propició la dimisión del presidente de la Cámara de los Comunes, Michael Martin, mientras que el primer ministro británico, Gordon Brown, anunciaba una serie de reformas sin precedentes para evitar un escándalo similar. Ningún presidente de los Comunes había abandonado el cargo a la fuerza desde 1695, cuando John Trevor se vio obligado a renunciar por aceptar un soborno de mil guineas. Según El País (OpPENHEIMER y GómEZ, 2009) existía la sospecha generalizada de que The Daily Telegraph había pagado para obtener los disquetes informáticos con toda la información de los gastos de los diputados desde hacía cinco años y se sospechaba que esa información había sido robada por un funcionario del Parlamento. Scotland Yard cerró la investigación al estimar el presunto interés público de la información alegado por el diario.

Para algunos teóricos, la información es una mercancía, un bien o servicio para el que existe demanda y que, por ende, tiene un valor. De hecho, las agencias de prensa generan beneficios por la venta de información que después podrá ser procesada o reelaborada por los medios de comunicación. En otros casos, y a raíz de la crisis económica, cada vez más medios optan por pagar informaciones a periodistas freelance ¿Por qué, entonces, las fuentes no pueden obtener beneficios por el suministro de información?

En contra de estas prácticas periodísticas, los argumentos se multiplican. Ron F. SмIтH (2003: 187-189), en su libro Groping for ethics in journalism, aporta cuatro argumentos de peso. El primero de ellos apunta a que la fuente puede mentir o exagerar los hechos cuando cobra por la información que aporta y, de igual manera, pueden surgir nuevos candidatos dispuestos a llevarse una parte del jugoso pastel. De hecho, en 1992, después de que el tabloide Star le pagara a una chica por confesar su affair con Bill Cinton, varias mujeres se ofrecieron al Washington Times dispuestas a idear aventuras afines.

En segundo lugar, puede generalizarse la costumbre de cobrar por aportar información hasta el extremo de que se oculte información a menos que alguien pague. Tras el 11-S, por ejemplo, muchos ciudadanos anónimos ofrecían a los medios sus testimonios, fotografías o vídeos a cambio de dinero. En tercer lugar, porque potencialmente puede bajar la calidad del trabajo periodístico. En este sentido, en las entrevistas concedidas previo pago las preguntas suelen estar circunscritas a unos límites preestablecidos y no se lleva al entrevistado a situaciones delicadas. En cuarto lugar, Ron F. SMIтH aporta un argumento financiero: la posibilidad de que estos pagos desencadenen una espiral de gastos entre los distintos medios que compiten por las exclusivas.

En cualquier caso, desde algunos sectores se entiende que el valor de la información es un concepto relativo en el que a veces nos encontramos con una tierra de nadie.

Bob Steele, director del programa ético del Poynter Institute for Media Studies, indica en este sentido que es difícil establecer con exactitud dónde empieza y dónde termina el periodismo de chequera. ¿Se trata simplemente del pago en efectivo por en- 
trevistas en exclusiva, o se extiende también al pago por consejos para la elaboración de noticias, aportación de información de background o datos antecedentes, y todavía más, imágenes y vídeos para ilustrar informaciones? Y, por otro lado, ¿se paga siempre en efectivo? ¿Y quién aporta la información, alguien implicado en la historia o un observador casual? (HEYBOER, 1999).

Como indica Claire HiLl (2002), el término periodismo de chequera puede cubrir una amplia variedad de áreas difíciles de clasificar, sobre las que a menudo hay desacuerdo. Es fácil diferenciar los pagos en efectivo, pero también pueden adoptar la fórmula de artículos de lujo, facturas legales, honorarios de consultoría, alojamiento y viajes.

David Perel, editor ejecutivo del National Enquirer, incide en este aspecto cuando afirma que el pago no siempre se realiza con dinero en efectivo, sino que incluye otras posiblidades como viajes gratuitos, publicidad gratuita (Michael Jackson negoció con $A B C$ News entrevistas a cambio de anuncios comerciales de 30 segundos) o, simplemente, los beneficios que pudiera reportar para la imagen el ser entrevistado por un periodista estrella (HeYBOER, 1999). Para un reportero con no demasiada experiencia puede resultar difícil saber cómo actuar en un contexto impreciso y sin regular, pero también pueden presentarse situaciones comprometidas para periodistas experimentados.

Ron F. Sмiтн (2003: 189) relata el caso de un periodista de The New York Times, John Tierney, que al escribir una serie de reportajes sobre personajes de las calles de Nueva York se encontró con que alguno de ellos le pedía 10 dólares por ser entrevistados, pese a que la cena que compartían con el reportero costaba 30 dólares. En otra ocasión, este periodista pagó a un drogadicto para que le hiciera un tour por zonas conflictivas de drogadicción, y lo hizo como si le pagara a un intérprete o a un guía turístico. ¿Cuántas veces los periodistas han conseguido información a cambio de un café caliente o un bocadillo? Entre los corresponsales en el extranjero y enviados especiales llega a ser una costumbre cara (HEYBOER, 1999).

La clave no sólo está en el dinero, sino también en la intencionalidad, de manera que el debate sobre los métodos para garantizar una exclusiva entra de lleno en el ámbito de la ética periodística. ¿Vale cualquier método para proteger y garantizar noticias en exclusiva a toda costa?

\section{Regulación ética}

Los distintos códigos éticos que regulan el ejercicio de la profesión periodística abordan la relación del periodista con las fuentes de manera genérica, con conceptos generales como la equidad, la dignidad, la ética o la legalidad, sin entrar en detalles. El código ético de la Federación Internacional de Periodistas (FIP), por ejemplo, advierte que el deber primordial del periodista debe ser "respetar la verdad y el derecho que tiene el público a conocerla" (art. 1). Posteriormente, la FIP indica que "el periodista no recurrirá sino a medidos equitativos para conseguir informaciones, fotografías y documentos" (art. 4).

El Código Deontológico Europeo de la Profesión Periodística, aprobado por la Asamblea Parlamentaria del Consejo de Europa en Estrasburgo el 1 de Julio de 1993, incide en aspectos afines: "En el ejercicio del periodismo el fin no justifica los medios, por lo que la información deberá ser obtenida a través de medios legales y éticos" (art. 25). Ade- 
más, el artículo 15 destaca que "desde la empresa informativa la información no debe ser tratada como una mercancía sino como un derecho fundamental de los ciudadanos".

Por su parte, el Código Deontológico de la Federación de Asociaciones de la Prensa de España (FAPE), aprobado el 27 de noviembre de 1993, especifica que "en el desempeño de sus obligaciones profesionales, el periodista deberá utilizar métodos dignos para obtener la información, lo que excluye los procedimientos ilícitos" (art. 14).

En lo que respecta a Estados Unidos, pocos medios disponen de normas escritas al respecto. Un análisis realizado por el Poynter Institute entre los códigos éticos de 33 periódicos revelaba que tan sólo la mitad disponían de pasajes significativos sobre las relaciones con las fuentes informativas y muy pocos incluían una referencia expresa a desaconsejar pagar a las fuentes por la información (HEYBOER, Kelly: 1999). Pese a ello, el código ético de la Sociedad de Periodistas Profesionales (Society of Professional Journalists, SPJ) indica textualmente que los periodistas deberían "avoid conflicts of interest, real or perceived" $\mathrm{y}$ "be wary of sources offering information for favors or money; avoid bidding for news"'2. Esta asociación ha manifestado su preocupación por la creciente recurrencia al periodismo de chequera, las cantidades de dinero que se barajan y las extravagantes fórmulas de pago que se emplean. En el 2009, la cadena $A B C$ pagó a los abuelos de Caylee Anthony, una niña de tres años asesinada en Orlando, tres noches de hotel como parte del trato de la cadena para entrevistarles, aunque la cadena se defendió argumentando que muchos programas pagan el alojamiento a sus invitados (STRUPP, 2010).

En Gran Bretaña, donde se trata de una práctica generalizada, en 2003 se abría nuevamente el debate a raíz de una serie de escándalos, como el intento de secuestro de Victoria Beckham y el pago a testigos de este suceso criminal. Un año antes, según Nick Higham (2003), se había amenazado con introducir cambios en la legislación para prohibir el pago a testigos. En este sentido, la comisión gubernamental que recibe las quejas de la prensa británica, la Press Complaints Comission ha censurado el pago a testigos envueltos en un suceso criminal una vez que el procedimiento judicial está activo, es decir, una vez que se han efectuado los arrestos; en etapas anteriores del proceso se permite, pero sólo con dos condiciones: si la información obtenida es de interés público y si el pago es el único medio de obtener la información.

\section{Estudio de caso: la entrevista del programa de Ana Rosa Quintana a Isabel García}

Isabel García es la mujer de Santiago del Valle, acusado junto a su hermana, Rosa del Valle, del secuestro y asesinato de la niña Mari Luz Cortés. Padece un retraso mental de moderado a leve. Coincidiendo con el final del juicio, en el que los dos acusados se declararon inocentes, Isabel García concedía una entrevista en exclusiva en "El programa de Ana Rosa", de la cadena de televisión Telecinco, en la que confesaba en directo, entre sollozos, y en contradicción con la declaración que había hecho en el jui-

1 Evitar conflictos de intereses, reales o percibidos.

2 Ser cauteloso con las fuentes que ofrecen información a cambio de favores o dinero; evitar pujar con noticias. 
cio previamente, que su marido había asesinado a la niña con ayuda de su cuñada. Los acusados se habían declarado inocentes en el juicio.

Tras su confesión televisiva, periodistas del programa la acompañaron a la Comisaría General de la Policía Judicial, en Madrid, donde pasó la noche en calidad de detenida para después ser puesta a disposición judicial. Isabel García volvía así a sus primeras declaraciones inculpatorias ante la Policía y en los juzgados en marzo de 2008. El juzgado de Instrucción número 43 de Madrid ordenó el ingreso en prisión sin fianza de Isabel García, acusada de los presuntos delitos de omisión del deber de impedir delitos y falso testimonio. Días después, tras acogerse a su derecho a no declarar, fue puesta en libertad provisional.

Al margen de la emisión en Telecinco, elmundo.es (2011) cargó en su web lo que no pudo verse en la emisión oficial, un descanso de la entrevista en el que la mujer pedía reiteradamente que no la grabaran más y entre lágrimas decía encontrarse mal y estar a punto de perder el conocimiento. Mientras tanto, la periodista que la acompaña le ayuda a sentarse en el suelo de un parque mientras continúa la grabación y le ofrece agua. Isabel García habla con alguien por el móvil y le dice no saber dónde está. "Ahora no te puedo decir dónde estoy, Ahinoa, no me encuentro muy bien ahora para hablar contigo, estoy ocupada, no sé dónde estoy, no conozco Madrid, lo siento mucho". Un miembro del equipo le indica por señas a Isabel que no diga dónde está. Isabel García pide entre lágrimas que acaben las entrevistas. "Más cámaras no, por favor". Las cámaras siguen grabando por indicación de la entrevistadora. Tras la insistencia de Isabel, la periodista pide finalmente que paren de grabar y pide permiso para llevarla a tomar algo. "Me la voy a llevar, porque no me la va a quitar nadie. Y no va a hablar con nadie más". No se sabe exactamente cómo elmundo.es consigue este vídeo, aunque según Mariola CuBELls (2011), la versión más probable apunta a un fallo en la conexión satélite, que no se codificó, y que por tanto habría llegado a otros medios, que capturaron la imagen y la filtraron.

Cuarzo TV, la productora que realiza "El programa de Ana Rosa", asegura que se pagaron los gastos de hotel y la comida y que la llamada que recibió Isabel García en el transcurso de la entrevista era de otra cadena, y no iban a permitir que se la llevaran. Ana Rosa Quintana, por su parte, también ha advertido que en ningún momento se forzó la confesión, y que dieron la noticia "que todo buen periodista hubiera querido dar" (Telecinco, 2011). Pero según El Mundo, durante los días previos, los miembros de la productora Cuarzo acompañaron a Isabel García durante las veinticuatro horas del día para evitar que pudiera entrar en contacto con nadie y cuando alguien encontraba el rastro, evitaban el contacto y cambiaban de lugar (RUIZ, 2011).

El Confidencial.com, que recoge las declaraciones de García Zabas, abogado de Isabel García, corrobora estos datos y afirma que varios periodistas estuvieron a su lado permanentemente durante diez días, en Sevilla y en Madrid, y la alojaban en buenos hoteles mientras que ellos dormían en habitaciones contiguas, y la llevaban a restaurantes. Tras varios días de acompañamiento fuera de la capital, se desplazaron hasta una población cercana a Madrid donde reside un antiguo novio de Isabel García al que ella quería ver y le prometen incluso 600 euros por la entrevista que nunca llegaron a abonar, según García Zabas (HernándeZ, 2011). Joaquina Prades y Rosario G. 
GómEZ escriben en El País que la pregunta que efectuaron a una persona vinculada a la cadena sobre si en algún momento habían advertido a la mujer de que confesar la autoría del marido significaba autoinculparse de varios delitos quedó sin respuesta, al igual que otras fuentes callaron al ser preguntadas por la cuantía de lo pagado por la exclusiva. Y añade: "Puede que fuera dinero en efectivo o tal vez solo obtuvo a cambio la satisfacción de aparecer en la tele con la Ana Rosa, acudir a hoteles y restaurantes de lujo y ser el centro de atención de un colectivo durante unas horas".

Las reacciones no se hicieron esperar, no sólo por el modo en el que se había conseguido la confesión en directo, justo el último día del juicio contra Santiago del Valle, sino también por el tratamiento que se le da a la entrevistada. La Federación de Asociaciones de Periodistas de España (FAPE) y la asociación Telespectadores Asociados de Cataluña (TAC), entre otras organizaciones de profesionales, insisten en que en periodismo "no todo vale".

La magistrada ha decretado el sobreseimiento de las actuaciones respecto a Gestevisión Telecinco, la productora Cuarzo, Ana Rosa Quintana y otros ocho periodistas al no haber apreciado que las personas que fueron imputadas en este procedimiento procediesen en algún momento a violentar física o psíquicamente la voluntad de Isabel García.

La resolución judicial añadía que durante la grabación se apreciaba que al finalizar la entrevista Isabel García estaba "serena y tranquila". Por su parte, la interesada ha recurrido el archivo de la causa.

\section{Conclusiones}

La rivalidad entre medios, y especialmente entre cadenas de televisión, ha propiciado una escalada sin límites para conseguir informaciones en exclusiva a cualquier precio. Aunque la prensa de calidad se intenta desmarcar de esta tendencia y las críticas por parte de profesionales y asociaciones son acuciantes, el periodismo de chequera se practica sin reparos.

La revisión de casos representativos de la última década evidencia, por otro lado, los numerosos matices que puede adoptar el concepto en cuanto a los agentes que intervienen en el proceso, la mercancía que se comercializa y, sobre todo, las formas de pago, entre las que el desembolso de efectivo es tan sólo una modalidad.

En lo que respecta a los agentes que intervienen en el proceso, puede tratarse de personajes directa o indirectamente relacionados con la información que se aporta, pero también de testigos que han presenciado un suceso (información primaria), o testigos a los que les han contado cómo ocurrió un suceso (información secundaria), o incluso testigos u observadores a los que les contaron que alguien contó cómo ocurrió un suceso (información terciaria). Los actores pueden ser igualmente personajes anónimos o conocidos.

La mercancía que se comercializa también adopta numerosas variantes, desde bienes intangibles, como entrevistas en exclusiva, declaraciones, datos o pistas para el desarrollo de una investigación, aportación de background o datos antecedentes, asesoramiento para la elaboración de noticias y reportajes, hasta bienes tangibles, como fotografías y vídeos en exclusiva. 
Por otro lado, frente al tradicional desembolso en efectivo, que puede alcanzar sumas cuantiosas, dependiendo del valor que cada medio otorgue a la información en un mercado de ofertas y demandas, han surgido fórmulas extravagantes como el pago con otros bienes tangibles como artículos de lujo, inserciones publicitarias, alojamientos, viajes o intangibles, como gestiones o favores. Algunos autores hacen referencia incluso a pagos no aparentes, como el prestigio o los beneficios para la imagen que pueda reportarle a un personaje el ser entrevistado por un periodista ampliamente reconocido. El valor de la información es, en cualquier caso, un concepto relativo que rara vez se corresponde con la calidad del producto que se ofrece.

En esta amplitud de parámetros se perfilan unos límites imprecisos y algunas prácticas difíciles de clasificar, sobre las que no existe un consenso generalizado desde el punto de vista deontológico (los códigos éticos apenas hacen referencia a esta cuestión). A veces puede resultar difícil saber cómo actuar en un contexto impreciso y sin regular. ¿Qué implica pagar una información a cambio de un café caliente, un bocadillo o un paquete de tabaco? ¿Y pagar el alojamiento a un entrevistado? ¿Se trata de cortesía o periodismo de chequera?

A falta de estudios que profundicen en estos aspectos, tan sólo el sentido común y el criterio ético puede orientarnos. Lo que identifica al periodismo de chequera es, desde luego, la finalidad: la existencia de un acuerdo para proteger una exclusiva a toda costa. Los mecanismos para proteger la exclusiva abarcan un amplio abanico de métodos, unos más que otros cuestionables desde el punto de vista de la ética periodística. De hecho, existen posturas encontradas entre los profesionales y teóricos y entre los distintos países donde se practica el periodismo de chequera sobre las virtudes y peligros que entraña el pagar por las informaciones.

Pero no todo vale por conseguir información. Hay, desde luego, situaciones descabelladas, al margen de la lógica, como la ocultación de una fuente, la retención, las falsas promesas, la coacción, que desvirtúan, en todo caso, el ejercicio de la profesión periodística y restan credibilidad a un oficio que sólo tiene sentido en un contexto de libertad.

\section{Referencias bibliográficas}

BOYNTON, Robert (2008): "Checkbook Journalism Revisited", en Columbia Journalism Revie, $\mathrm{n}^{\mathrm{o}}$ enero/ febrero: http://www.cjr.org/essay/checkbook_journalism_revisited.php, [Fecha de consulta: 31-01-2011]

CUBELLS, Mariola (2011): “Cuando juzga la TV", en: Adn.es, 1 de marzo: http://www.adn.es/tv/20110301/NWS-0172-TV-juzga.html [Fecha de consulta: 0203-2011]

EL MUNDO (2011): "La Justicia investigará la actuación de Telecinco y del programa de Ana Rosa", en: El Mundo, edición digital, 28 de febrero: http://www.elmundo.es/ elmundo/2011/02/26/television/1298745496.html [Fecha de consulta: 28-02-2011]

EL PAÍS (2010): Entrevista de los internautas a Javier Moreno, en: El País on line, 29 de noviembre: http://www.elpais.com/edigitales/entrevista.html?encuentro=7439 [Fecha de consulta: 15-01-2011] 
FARHI, Paul (2010): “Up for audit: 'Checkbook journalism' and the news groups that buy big stories", en: The Washington Post on line, 17 de noviembre: http://www.washingtonpost.com [Fecha de consulta: 26-02-2011]

HERNÁNDEZ, Esteban (2011): "El periodismo, la justicia y una confesión de 600 euros", en Elconfidencial.com, 5 de marzo: http://www.elconfidencial.com [Fecha de consulta: 06-03-2011]

HEYBOER, Nelly (1999): "Paying For It", en American Journalism Review, April: http://www.ajr.org/article.asp?id=461 [Fecha de consulta: 17-01-2011]

HIGHAM, Nick (2003): "Chequebook journalism in the dock", en BBC on line, 3 de junio: http://news.bbc.co.uk/2/hi/uk_news/england/2957982.stm [Fecha de consulta: 23-01-2011]

HILL, Claire (2002): “Is there a future for checkbook journalism?", en: Hackwriters, mayo: http://www.hackwriters.com/Checkbookjournalism.htm [Fecha de consulta: 20-01-2011]

LONGHI-BRACAGLIA, Isabel (2008): "La exclusiva de Julián Muñoz cuesta 350.000 euros a Telecinco", en El Mundo edición on line, 5 de noviembre: http://www.elmundo.es [Fecha de consulta: 01-01-2011]

OPPENHEIMER, Walter y GÓMEZ, Rosario G. (2009): "El periodismo de chequera tienta", en El País edición digital, 22 de mayo: http://www.elpais.com [Fecha de consulta: 09-02-2011]

PRADES, Joaquina y GÓMEZ, Rosario G. (2011): “¿Le juzga el juez o le juzga el circo?", en: El País edición digital, 1 de marzo: http://elpais.com/diario/2011/03/ 01/sociedad/1298934001_850215.html [Fecha de consulta: 01-03-2011]

RUIZ, Vicente (2011): "Me la voy a llevar, no me la quita nadie", en El Mundo, 27 de febrero, edición Andalucía, p. 28.

SMITH, Ron F. (2003): Groping for ethics in journalism. Iowa, Blackwell Publishing, 2003.

STRUPP, Joe (2010): "SPJ Issues Major Statement Condemning 'Checkbook Journalism"”, en: Media Matters for America, 24 de marzo: http://mediamatters.org/ blog/201003240053 [Fecha de consulta: 24-03-2011]

SOCIETY OF PROFESSIONAL JOURNALISTS (SPJ): Code of Ethics, en página web de la Sociedad de Periodistas Profesionales: http://www.spj.org/ethicscode.asp [Fecha de consulta: 24-02-2011]

Telecinco (2011): "Ana Rosa: "Isabel decidió contar libre y voluntariamente la verdad", en: Telecinco.es, 28 de febrero: http://www.telecinco.es/elprogramadeanarosa/detail/detail28953.shtml [Fecha de consulta: 02-03-2011] 